\section{PUSHING ON WITH EXPANSION}

CT Dent - the UK's only independent dental scanning company - is building on its success, with a string of new practices opening across the country.

The firm has recently opened new premises in Bristol, Nottingham, Kent and Leeds. This adds to existing CT Dent practices in London, Manchester and Birmingham.

More dentists than ever are now accessing the benefits of using CT Dent, which include:

- Access to a dedicated CQC-accredited scanning service, meaning you never have to refer a patient to a hospital or a competitor again

- Quality scans made using the KAVO DP800 (2015 model) scanner - the latest in CBCT technology

- All scans carried out by trained radiographers

- Exceptional customer service that has led to 98\% positive customer feedback

- New PACS software that allows you to view and manipulate scans on any tablet, smartphone or

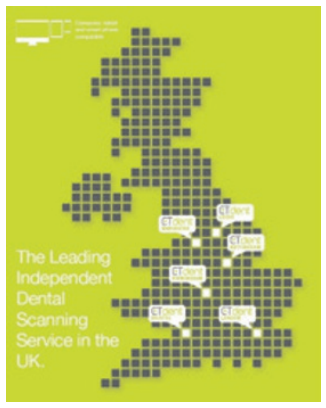
computer.

Over 4,000 dental practices across the UK already trust CT Dent with their scanning requirements.

To join them and start referring patients today, simply register for free on the CT Dent website - www.ct-dent. co.uk

\section{A RESTORATIVE THAT GOES WITH THE FLOW}

Kerr's team knows that direct procedures require multiple technological solutions. That's why we have created a robust family of universal composites with a variety of different handling characteristics and property values.

Take, for example, Herculite XRV Ultra Flow, a medium viscosity light cure nanohybrid resin restorative that combines the long-standing expertise of the Herculite brand with an innovative flowable composite.

Formulated with Kerr's rheological expertise, Herculite XRV Ultra Flow, thanks to its Smart Placement Technology, is able to flow easily when used as a base/liner and maintain its shape when used in small restorations. Other features include:

- Outstanding flexural strength

- Low shrinkage

- Easily polished

- Excellent gloss retention.

The Herculite XRV Ultra range offers the best of both worlds - strength and aesthetics - to give you long-lasting, beautiful restorations.

For further information, call 01733 892292, email kerruk@kerrhawe.com or visit www.kerrdental.co.uk.

\title{
'FAST TRACK' FUNDING SOLUTION LAUNCHED
}

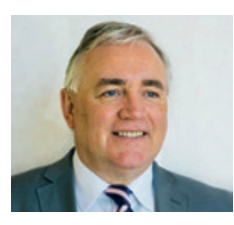

Braemar Finance has launched its new funding solution, 'Fast Track' which enables den-

tistry, veterinary, legal and funeral sector customers to apply for a credit facility to finance a selected medical procedure, treatment or specific professional service.

Fast Track is designed both for sole practitioners/small partnerships and larger corporate groups who want to be able to offer a no-frills funding option to their clientele. It is available online and consumers can either request funds whilst on the business premises of their dentist, vet, solicitor or funeral service, or at home at a time that suits them. Endusers will then be provided with an instant decision to their application.

\section{A NEW PARTNERSHIP}

American Express UK and Henry Schein Dental UK has announced a new partnership. Under the new alliance, Henry Schein Dental will welcome American Express Cards and provide its customers access to American Express payment products, such as the American Express Gold Business Card for Henry Schein Dental customers.

Andy Sloan, Head of Business Solutions at Henry Schein, said: 'The launch of the partnership with American Express demonstrates our strategy of helping dental practices become great businesses. Since the launch of Business Solutions we

\section{NOW LATEX-FREE!}

Xylocaine Standard from DENTSPLY is the first choice for General Dental Practitioners requiring the adrenaline based local anaesthetic and is now latex free.

By introducing another line of latex free anaesthetic to their range, DENTSPLY aims to support the dentist in helping avoid any potential allergic reactions in patients, thus
Professional services firms can register for Fast Track by providing Braemar Finance with the relevant information about their business. They will then be offered choices from the interest free and interest bearing options with terms that best suits the SME's business and their customers.

Furthermore, the dedicated Braemar Finance team will provide introduction and training sessions to identify ways the Fast Track solution can best enhance the SME's business objectives.

David Foster, managing director at Braemar Finance (left), said: "At Braemar Finance we take time to listen and understand our clients. That's why we created Fast Track, which offers a funding solution to help SMEs and their own clients.'

For more information visit www. braemarfinance.co.uk or call 0156 3898388.

have partnered with leading companies that can offer real value to our customers, warmly accepting American Express and offering our customers a bespoke Gold Business Card offer epitomises this strategy.'

Stacey Sterbenz, Director, American Express Small Business Services UK, said: 'American Express is delighted to launch its partnership with leading dental supplier Henry Schein at such a significant event in the dental calendar.'

To find out more about the American Express Gold Business Card for Henry Schein Dental customers, contact your Henry Schein Dental sales representative.

ensuring a more comfortable dental experience. What's more, latex free Xylocaine Standard is competitively priced, and can help towards reducing costs at the practice.

For more details contact DENTSPLY UK on 0800072 3313 or visit dentsply.co.uk.

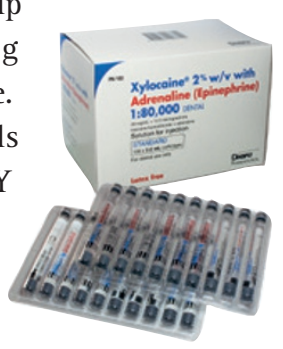

